\title{
Hypochlorite Accident through Perforation: A Sequence of Iatrogenic Accidents
}

\author{
Noor I Othman ${ }^{*}$ \\ ${ }^{1}$ Centre for Comprehensive Care Dentistry, Faculty of Dentistry, Universiti Teknologi Mara, Malaysia \\ *Corresponding Author: Noor I Othman, Centre for Comprehensive Care Dentistry, Faculty of Dentistry, \\ Universiti Teknologi Mara, Malaysia; Email: yayaothman@gmail.com
}

Received Date: 26-01-2022; Accepted Date: 16-02-2022; Published Date: 22-02-2022

Copyright $^{\oplus} 2022$ by Othman NI. All rights reserved. This is an open access article distributed under the terms of the Creative Commons Attribution License, which permits unrestricted use, distribution and reproduction in any medium, provided the original author and source are credited.

\begin{abstract}
The most generally utilized root channel water system arrangement is sodium hypochlorite $(\mathrm{NaOCl})$. It is utilized at convergence of $0.5 \%-5.25 \%$ and is powerful against most endodontic microorganisms for example Enterococcus, Actinomyces and yeast. At $0.5 \%-1 \%, \mathrm{NaOCl}$ breaks down just necrotic tissue however at a higher focus, it disintegrates both necrotic and fundamental tissue. It has little impact on inorganic tissue. Though $\mathrm{NaOCl}$ is disliked in light of the fact that it has a horrendous taste, harmfulness and spills can demolish a patient's clothing because of its dying impact. It enjoys the benefit of decreasing the acidic impact on the periradicular tissues while keeping up with the truly necessary antibacterial property.
\end{abstract}

Inaccurate assurance of endodontic working length, iatrogenic broadening of the apical foramen, parallel hole, or wedging of the flooding needle are the normal variables of the subject. Obviously, safety measures should be embraced to forestall such accidents. The patient's clothing ought to be safeguarded successfully against the irrigant, as well as the patient's and administrator's eyes. The flooding needle should be fixed to the needle and should not be wedged into the root channel.

From this case, clearly the area of the hole is a vital data. During water system a low and consistent tension should be utilized and all abundance irrigant leaves the root waterway coronally through the entrance hole with the assistance of a fast attractions. Root holes might prompt tooth extraction. It is a generally expected confusion of endodontic treatment or post

Othman NI | Volume 3; Issue 1 (2022) | JDHOR-3(1)-040 | Case Report

Citation: Othman NI, et al. Hypochlorite Accident through Perforation: A Sequence of Iatrogenic

Accidents. J Dental Health Oral Res. 2022;3(1):1-7.

DOI: http://dx.doi.org/10.46889/JDHOR.2022.3103 
readiness. Fruitful administration relies essentially upon quick fixing of the hole subsequently anticipation of contamination. A few variables decide the accomplishment of these objectives, generally significant of which are: season of event, size and area of the hole.

\section{Keywords}

Ulcer; Endodontic; Root Canal System; Endodontic Microorganisms

\section{Introduction}

The most widely used root canal irrigation solution is sodium hypochlorite ( $\mathrm{NaOCl})$. It is used at concentration of $0.5 \%-5.25 \%$ and is effective against most endodontic microorganisms e.g. Enterococcus, Actinomyces and yeast. At $0.5 \%-1 \%, \mathrm{NaOCl}$ dissolves only necrotic tissue but at a higher concentration, it dissolves both necrotic and vital tissue. It has little effect on inorganic tissue. Bystrom and Sundqvist (1985) therefore recommended concurrent use of demineralising agents to enhance cleaning of difficult to reach areas. Albeit $\mathrm{NaOCl}$ is unpopular because it has an unpleasant taste, toxicity and spills can ruin a patient's clothing due to its bleaching effect.

According to Roda (2001), root perforation repair has always been an unpredictable treatment with a high rate of failure. When the perforation is below the orifice, appropriate planning and a careful conventional root canal treatment with a thorough chemical debridement is necessary. Giovarruscio et al. (2020) suggested the use of $1 \% \mathrm{NaOCl}$ in cases with perforation. It has the advantage of reducing the caustic effect on the periradicular tissues while maintaining the much needed antibacterial property.

\section{Case Description}

A 21-year-old lady was referred from a final year undergraduate student for management of tooth 24 which presented with a buccal abscess. The abscess was accidentally ruptured while brushing. History of the presenting complaint is the tooth was endodontically treated a year earlier. 2 canals were obturated but a perforation was noted with regards to the palatal root. The patient is medically fit and is a regular dental attendee. She brushes once daily and uses mouthwash and flosses occasionally.

General examination revealed an asymmetrical face with Class II profile. Both of temporomandibular joints are sound, width of mouth opening is normal and lips are incompetent. Intraorally, there was presence of an ulcer at buccal sulcus of tooth $24(2 \mathrm{~cm})$.

Othman NI | Volume 3; Issue 1 (2022) | JDHOR-3(1)-040 | Case Report

Citation: Othman NI, et al. Hypochlorite Accident through Perforation: A Sequence of Iatrogenic

Accidents. J Dental Health Oral Res. 2022;3(1):1-7.

DOI: http://dx.doi.org/10.46889/JDHOR.2022.3103 
Pus discharge from the lesion was noted. Tooth 24 was with a molar band and a GIC occlusal restoration. Other teeth are sound, with no active caries and her oral hygiene is fair (Fig. 1).

Upon investigation, tooth 24 was firm but tender to percussion. Multiple periapical radiographs were taken to help evaluation and treatment planning. From the attached radiograph, it is noted that the canal has been obturated albeit not well condensed. There is also presence of a radiopaque object which appeared to be outside of the roots and is in the periradicular tissue (Fig. 2).

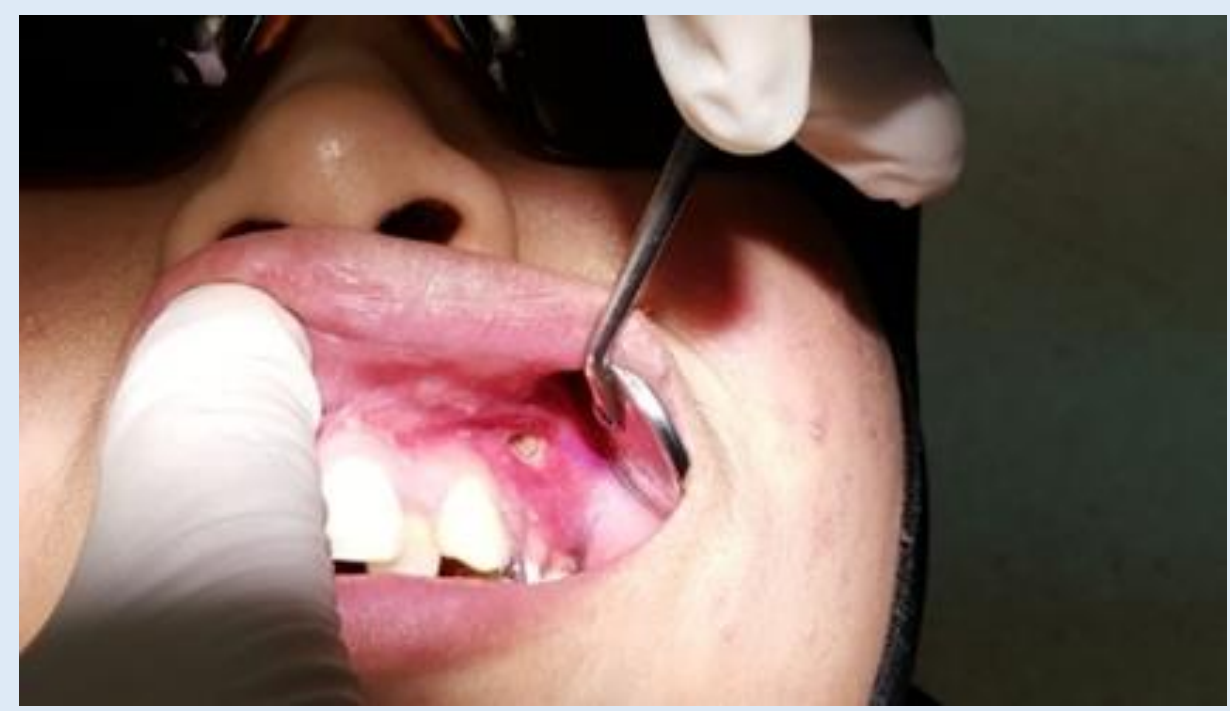

Figure 1: Ulcer presented at buccal of tooth 24.

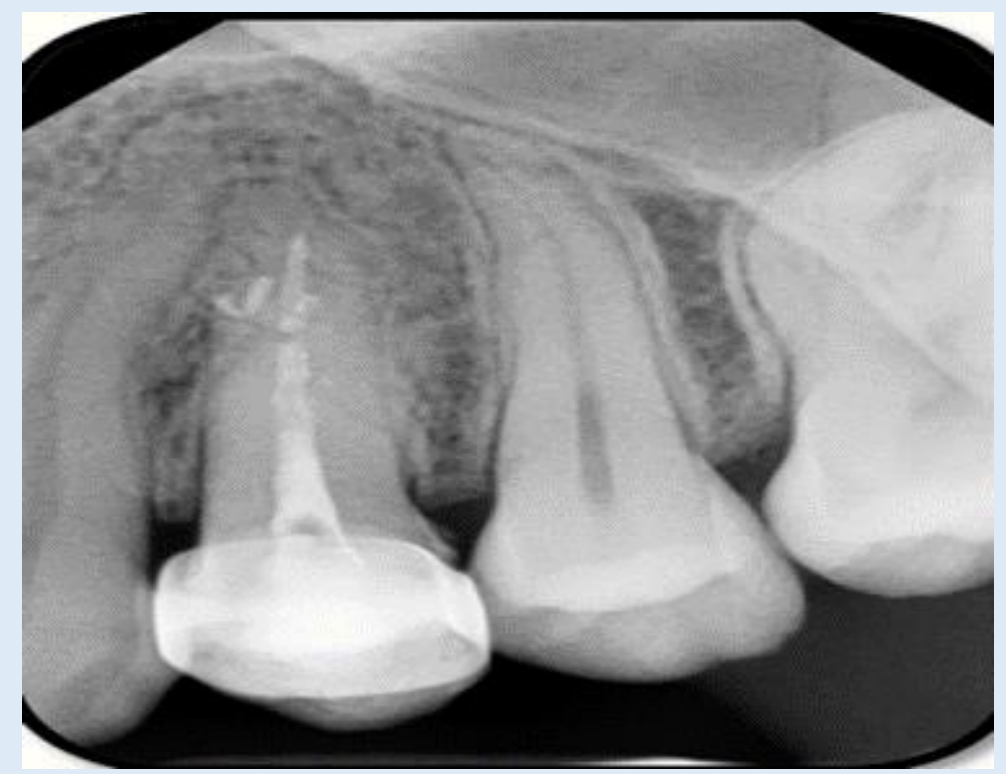

Figure 2: Intraoral periapical radiograph showing obturation for tooth 24 .

Othman NI | Volume 3; Issue 1 (2022) | JDHOR-3(1)-040 | Case Report

Citation: Othman NI, et al. Hypochlorite Accident through Perforation: A Sequence of Iatrogenic Accidents. J Dental Health Oral Res. 2022;3(1):1-7. 
Local anaesthesia injection was done at the beginning of every appointment prior to rubber dam isolation. Access cavity was made from occlusal surface of 24 , same access made from previous root canal treatment. Inside the pulp chamber, GIC removed until obturation material from both canal orifices seen.

2 canals located and obturation material from both canals removed using chloroform and retreatment rotary files. When both canals are clean from obturation material, irrigation with sodium hypochlorite was carried out and patient suddenly felt an acute pain. Hypochlorite accident was suspected, an ice pack was placed onto upper left cheek of patient to ease the pain. Access cavity was quickly restored with temporary restoration and patient was dismissed with prescribed painkillers.

Patient was contacted the day after, she informed that her left upper cheek is bruised and swollen of a size of a golf ball. The area is also tender to palpation. Patient was asked to come to the clinic for expert management. Intraorally, an ulcer was present at buccal of tooth 24 with thick yellowish mucus-like discharge. Patient was febrile and her upper left cheek was bluish in colour. Drainage of buccal area of 24 was done under local anaesthesia, excavation to remove thick mucus was also carried out. Ice pack placed on left cheek to ease tenderness. Patient was dismissed with painkillers and assurance.

Working length determination was done via periapical radiographs in the third visit. Soft tissue and mucosae surrounding tooth 24 was inspected for any abnormality, ulcer appeared healing and patient was comfortable and afebrile. Working length for both canals were accepted at the patent length. It was noted there are 2 perforations, each inside buccal and palatal canal. Cleaning and shaping of all canals were completed using sodium hypochlorite, EDTA and ProTaper Next ${ }^{\circledR}$ rotary files. For both canals, ultrasonic chemical irrigation with sodium hypochlorite was done to ensure total debridement of the root canal system. Extra care was taken to avoid another hypochlorite accident.

During the fourth visit, obturation was carried out since there is no sign and symptoms, patient had no complain and soft tissue and mucosae surrounding the tooth has healed. Orifice barrier placed prior to placement of permanent composite restoration. Molar band removed and occlusion was checked (Fig. 3). 


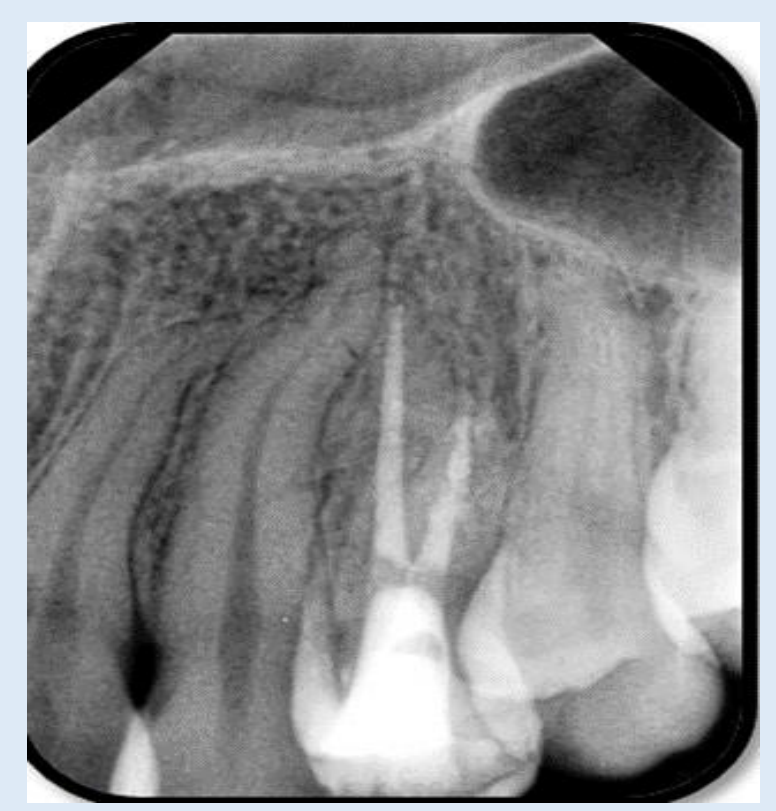

Figure 3: Intraoral periapical radiograph showing completed root canal treatment for tooth 24.

\section{Discussion}

A major complication of endodontic and restorative treatments is accidental perforation of the roots or the pulp chamber floor. Such perforation may occur during nonsurgical root canal treatment or during preparation for a variety of restorative procedures (Tsesis \& Fuss, 2006). The result is a chronic inflammatory reaction of the periodontium (characterized by the formation of granulation tissue) that can lead to irreversible loss of attachment or loss of the tooth (Al Daafas \& Al Nazhan, 2007). Such perforations are managed surgically or nonsurgically, depending on the particular characteristics of the case (Roda, 2001). The prognosis may be questionable if treatment involves a lesion occurring at the level of the radicular furcation, but the prognosis is usually good if the problem is diagnosed correctly and treated with a material having suitable sealing ability and biocompatibility (Tsesis \& Fuss, 2006). The prognosis also depends on the location, size and time of contamination of the lesion. Several factors would lead to iatrogenic perforations. These include aberrant canal morphology, error by practitioner while gaining access to the pulp chamber, failure during chemical and mechanical preparation due to inadequate canal wall preparation, calcifications and preparation for intracanal post placement. Perforations can also be caused by practitioner negligence, recklessness, or inexperience. With regards to this case, perforations of the root canals were done by undergraduate students. One might think that the lack of experience could be the main factor of the procedural error. Alves et al. (2013) found the frequency of procedural errors was low for either NiTi or stainless steel endodontic instruments even though manipulated by inexperienced operators. When located in the furcation or cervical third of the

Othman NI | Volume 3; Issue 1 (2022) | JDHOR-3(1)-040 | Case Report

Citation: Othman NI, et al. Hypochlorite Accident through Perforation: A Sequence of Iatrogenic Accidents. J Dental Health Oral Res. 2022;3(1):1-7. 
root, perforations have a negative impact on the prognosis of endodontic treatment. This is because an inflammatory reaction in the periodontal region is triggered and may lead to attachment loss and occasionally, tooth loss. A periodontal pocket may form depending on the crestal bone level and the degree of destruction in the region of the perforation. Once the alveolar bone is destroyed, granulation tissue is likely to form and may invaginate into the tooth through the perforation tract (Cogo et al., 2009).

In the present case, perforations were repaired by means of bypassing and routine obturation regime using gutta percha and resin sealer. Mineral Trioxide Aggregate (MTA) will be considered should a surgical repair of the perforations takes place in the future. As mentioned earlier, hypochlorite accident happened while endodontic treatment was carried out causing an acute pain to patient and treatment had to be stopped. In teeth with wide apical foramina, unintentional injection of sodium hypochlorite beyond the apical foramen may occur. This accident can also occur when the apical constriction has been destroyed during root canal preparation or by resorption. It can also be caused by a man-made foramen e.g. perforations during cleaning and shaping. Additionally, extreme pressure during irrigation or binding of the irrigation needle tip in the root canal with no release for the irrigant to leave the root canal coronally may result in contact of large volumes of the irrigant to the apical tissues. Just like in the present case, the extruded $\mathrm{NaOCl}$ with its excellent tissue-dissolving capability will lead to tissue necrosis.

A case report by Becker, et al., (1974) was very similar to the present case whereby after wedging the irrigation needle in the root canal, sodium hypochlorite was forced beyond the apex of a maxillary right cuspid which led to immediate strong reactions with extreme pain. Then, the patient's cheek and upper lip showed signs of haematoma and ecchymosis inferior to the right zygoma and profuse haemorrhage from the root canal. Wet compresses were continuously applied to relieve the pain and the burning sensation felt by the patient. According to Becker, et al., (1974) although the swelling increased during the next few hours, the pain slowly diminished.

\section{Conclusion}

The endodontic literature contains numerous case reports on complications during root canal irrigation, including accidental injection of sodium hypochlorite or hydrogen peroxide into the periapical tissues, air emphysema and allergic reactions to the solutions. Incorrect determination of endodontic working length, iatrogenic widening of the apical foramen, lateral perforation, or wedging of the irrigating needle are the common factors of the subject. Clearly, precautions must be undertaken to prevent such mishaps. The patient's clothing should be 
protected effectively against the irrigant, as well as the patient's and operator's eyes. The irrigating needle must be fixed to the syringe and must not be wedged into the root canal.

From this case, it is obvious that the location of the perforation is a crucial information. During irrigation a low and constant pressure should be used and all excess irrigant leaves the root canal coronally via the access cavity with the help of a high speed suction. Root perforations may lead to tooth extraction. It is a common complication of endodontic treatment or post preparation. Successful management depends mainly on immediate sealing of the perforation thus prevention of infection. Several factors determine the achievement of these goals, most important of which are: time of occurrence, size and location of the perforation.

\section{Conflict of Interest}

The authors declare no conflict of interest exists.

\section{References}

1. Bystrom A, Sundqvist G. The antibacterial action of sodium hypochlorite and EDTA in 60 cases of endodontic therapy. Int Endodont J. 1985;18:35-40.

2. Tsesis I, Fuss Z. Diagnosis and treatment of accidental root perforations. Endodontic Topics. 2006;13:95107.

3. Al Daafas A, Al Nazhan S. Histological evaluation of contaminated furcal perforation in dogs' teeth repaired by MTA with or without internal matrix. Oral Surgery, Oral Medicine, Oral Pathology, Oral Radiology and Endodontol. 2007;103(3):e92-99.

4. Roda RS. Root perforation repair: surgical and nonsurgical management. Prac Proc Aesthetic Dent. 2001;13(6):467-72.

5. Cogo DM, Vanni JS, Reginatto T, Fornari V, Baratto Filho F. Materials used in the treatment of endodontic perforations. South Brazilian Dent J. 2009;6(2);195-2003.

6. Alves RAA, Souzaa JB, Goncalves Alencara AH, Pecora JD, Estrela C. Detection of procedural errors with stainless steel and NiTi instruments by undergraduate students using conventional radiograph and cone beam computed tomography. Iran Endodontic J. 2013;8(4):161-5.

7. Becker GL, Cohen S, Borer R. The sequelae of accidentally injecting sodium hypochlorite beyond the root apex. Oral Surgery, Oral Medicine and Oral Pathol. 1974;38:633-8.

8. Giovarruscio M, Tonini R, Zavattini A, Foschi F. Standardising reparative procedures for perforations. Endodontic Practice Today. 2020;14(3):217-28. 